\title{
CORRECTION
}

\section{Correction to: Case mixing impedes early lexical access: converging evidence from the masked priming paradigm}

\author{
Mei-Ching Lien ${ }^{1}$ (D) Philip A. Allen ${ }^{2}$ Eric Ruthruff ${ }^{3}$
}

Published online: 25 April 2020

(c) Springer-Verlag GmbH Germany, part of Springer Nature 2020

\section{Correction to: DOI: Psychological Research}

https://doi.org/10.1007/s00426-020-01305-4

Correction text:

In the original publication of the article, Fig. 1 is incorrect. The "\#s" should be only 5 instead of 6 . The legend for Fig. 2 top panel is incomplete for the "Lowercase Prime". It only shows a bar instead of a small white square. The correct Figs. 1 and 2 are given below:

Publisher's Note Springer Nature remains neutral with regard to jurisdictional claims in published maps and institutional affiliations.

The original article can be found online at https://doi.org/10.1007/ s00426-020-01305-4.

Mei-Ching Lien

mei.lien@oregonstate.edu

1 School of Psychological Science, Oregon State University, Corvallis, OR 97331-5303, USA

2 Department of Psychology, University of Akron, Akron, OH 44325-4301, USA

3 Department of Psychology, University of New Mexico, Albuquerque, NM 87131-0001, USA 
Fig. 1 An example event sequence for the mixed-case prime word and uppercase word target condition in Experiment 1. Note that the prime could be in mixed-case or lowercase whereas the target could be in uppercase or lowercase. In the real experiment, the font type for both prime and target words was Times New Roman
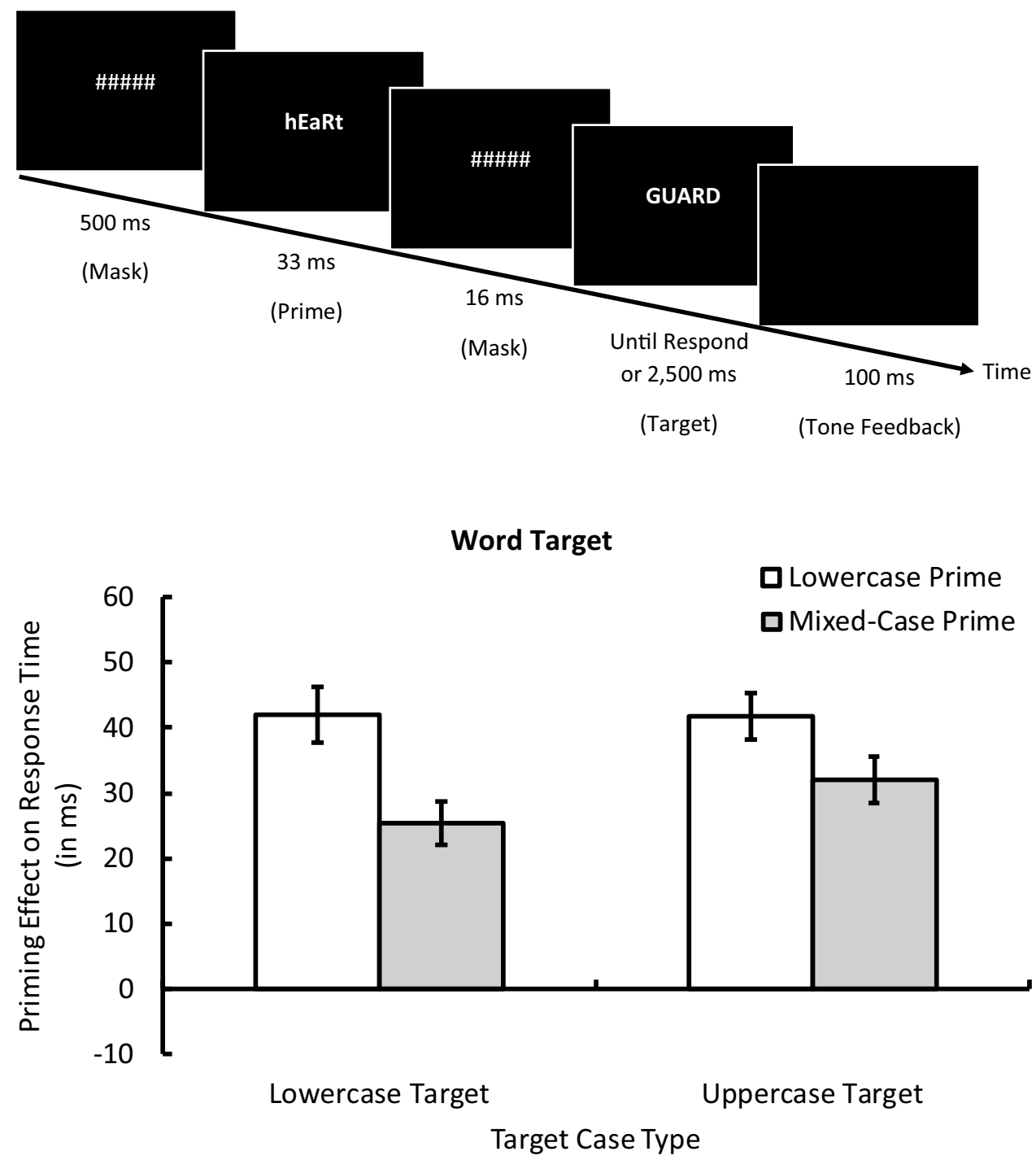

Nonword Target

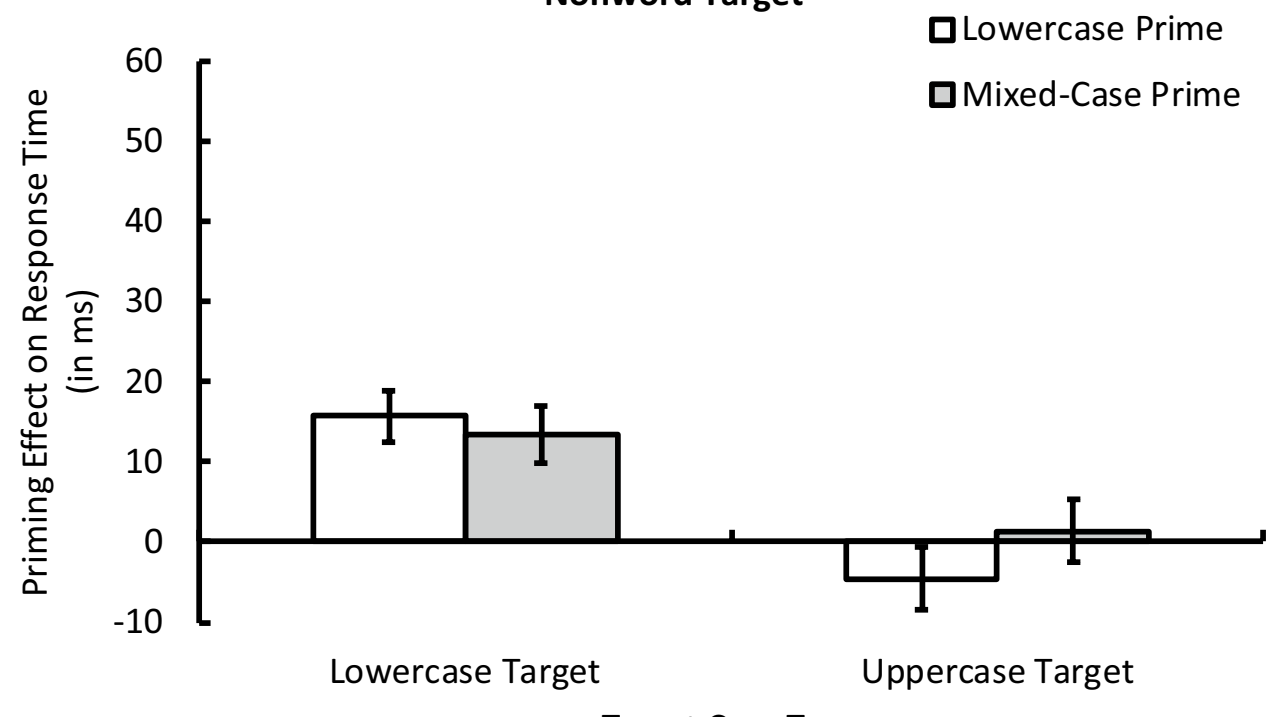

Fig. 2 Priming effect (unrelated prime-identity prime) on response time for word targets and nonword targets as a function of target case type (lowercase target vs. uppercase target) and prime case type (lowercase prime vs. mixed-case prime) in Experiment 1. Error bars represent the standard error of the mean for the priming effect

Target Case Type 